16

\title{
Влияние адсорбированных атомов металлов на поглощение света поверхностью кварца
}

\author{
(C) Н.Б. Леонов \\ Университет ИТМО, \\ 197101 Санкт-Петербург, Россия \\ e-mail: nikitaleonov@yandex.ru
}

Поступила в редакцию 09.07.2020 г.

В окончательной редакции 09.07.2020 г.

Принята к публикации 28.07.2020 г.

Исследованы оптические свойства субмонослойных металлических пленок - серебра, золота, индия, -
полученных методом лазерной абляции на поверхности плавленого кварца. Получены спектры экстинкции и
спектры поглощения кварца, подложек с напыленными пленками, а также разностные спектры. Определены
минимальные значения эффективных толщин металлических пленок, при которых начинается зарождение
островков и проявляются локализованные плазмонные резонансы. Показано, что поглощение комплекса
„варцевая подложка-металлическая пленка“ превышает сумму поглощений поверхностью кварца и атомами
металла. Указано на связь этого явления с передачей заряда от металла к дефектам на поверхности подложки.

Ключевые слова: адсорбция, плазмонный резонанс, дефекты, уровни Тамма, немостиковый атом.

DOI: $10.21883 /$ OS.2020.12.50333.192-20

\section{Введение}

Явления, возникающие при контакте металлов с диэлектриками, используются или оказывают существенное влияние как на работу ряда устройств, так и на протекание важных технологических процессов. В качестве примеров можно привести контакты микроэлектронных и фотовольтаических устройств, газовые сенсоры, катализ. Со времени первых публикаций на тему адсорбции атомов металлов прошло много лет, тем не менее до последнего времени появляются статьи, позволяющие глубже понять проблемы, возникающие при изучении адсорбции. Особенно это касается адсорбции атомов металлов на диэлектриках. Так, в [1] подробно рассмотрены взаимодействия изолированных атомов меди, палладия и цезия с поверхностью кварца на основе кластерных моделей. Авторы рассчитали энергию связей атомов металлов на различных местах подложки - как дефектах (немостиковые связи), так и регулярных структурах. В [2] с помощью UV-спектроскопии исследована адсорбция атомов цезия на различных диэлектриках, в том числе на кварце. В [3] с помощью рентгеновской электронной спектроскопии и других методов было исследовано поведение атомов меди, напыленных на тонкую пленку кварца, синтезированную на поверхности молибдена. В [4] экспериментально (с помощью метода EXAFS) было определено, что атомы серебра при адсорбции занимают места поверх атомов кислорода на поверхности подложки $\mathrm{MgO}(100)$ и определено расстояние между этими атомами. В [5] методом рентгеновской электронной спектроскопии продемонстрирована связь адсорбированных атомов цезия с мостиковым и немостиковым кислородом кварца. Влиянию физической и химической адсорбции, а также диффузии на послойное осаждение атомов (ALD) посвящен обзор [6].
От характера и условий адсорбции атомов металла на диэлектрической подложке зависят и свойства островковых пленок - положение и добротность плазмонных резонансов определяется формой островков [7], которая, в свою очередь, зависит от скорости диффузии атомов металла по поверхности диэлектрика.

В качестве подложки часто выбирается плавленый кварц - во многом благодаря его относительной дешевизне и легкости обработки. Плавленый кварц как оптический материал высокого качества часто используется в микроэлектронике, оптоэлектронике и оптических приборах. Электронная структура кварца изучена давно и подробно описана, например, в обзорах $[8,9]$. При этом существенную роль играет поверхность кварца. Свободные „оборванные“ связи кремния и кислорода (обычно называемые $E^{\prime}$-центрами и немостиковыми кислородными пустыми центрами (NBOHC) являются основными дефектами, присущими поверхности кварца. Оптическое поглощение оборванных связей кремния и кислорода находится в видимом и ближнем UVдиапазонах. Поверхностные дефекты на плавленом кварце могут быть очевидной причиной поглощения и могут ограничивать эксплуатационные качества приборов, в которых используется плавленый кварц [10].

В настоящей работе также изучается взаимодействие атомов некоторых металлов с подложкой из плавленого кварца и влияние этих металлов на оптические свойства дефектов поверхности подложки.

\section{Эксперимент}

Атомы металла осаждались на подложку из плавленого кварца методом лазерной абляции в самодельной 


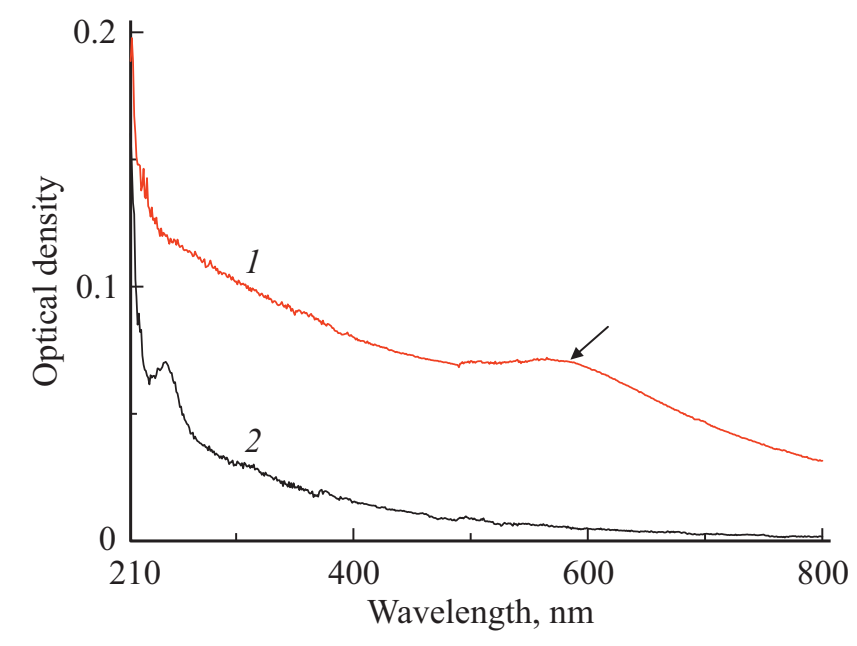

Pис. 1. Спектры экстинкции (зависимости оптической плотности OD от длины волны) пленок золота на плавленом кварце. Спектр экстинкции подложки вычтен. Кривые 1 и $2-$ спектры более толстой и более тонкой пленок. Стрелка указывает на плазмонный резонанс золота.

вакуумной камере, описанной в [11] при вакууме не хуже $10^{-5}$ Torr. Луч лазера, проходя через окно из плавленого кварца, фокусировался линзой, проходил через подложку, расположенную близко к линзе, и попадал на металлическую мишень. В качестве мишени использовались серебро, золото, индий. Чистота металлов была 99.99. В качестве подложки использовался полированный плавленый кварц высокой чистоты. Перед установкой в камеру подложка подвергалась очистке в ультразвуковой ванне, сначала в этаноле, затем в дистиллированной воде.

Источником света служил Nd:YAG-лазер, генерирующий импульсы длительностью $10 \mathrm{~ns}$ с частотой повторения от 1 до $10 \mathrm{~Hz}$, либо одиночные импульсы. Большая часть экспериментов была выполнена при освещении второй гармоникой, которой соответствует длина волны $532 \mathrm{~nm}$. Энергия одиночного импульса была около $75 \mathrm{~mJ}$. Излучение лазера фокусировалось на поверхность мишени в пятно диаметром $100 \mu \mathrm{m}$. Использованный лазерный метод напыления, в отличие от инерционных методов термического напыления или напыления электронным пучком, позволял получать очень тонкие пленки, варьируя энергию и количество лазерных импульсов.

Спектры экстинкции измерялись на спектрофотометре СФ-56 (ОКБ Спектр, Россия), спектры поглощения на спектрофотометре UV-3600 (Shimadzu, Япония).

\section{Результаты и их обсуждение}

Были получены спектры экстинкции тонких пленок золота и серебра, на которых видно зарождение пиков, соответствующих плазмонным резонансам в наночастицах этих металлов. На рис. 1 показаны такие спектры экстинкции золотых пленок разной толщины. При этом спектр экстинкции подложки из плавленого кварца вычтен, т. е. это разностный спектр. Стрелкой показан пик плазмонного резонанса, появляющийся около $600 \mathrm{~nm}$.

На рис. 2 показаны спектры экстинкции пленки серебра, напыленной на подложку, а также подложки из плавленого кварца. На этом же рисунке показан разностный спектр, который должен соответствовать экстинкции атомов серебра. На кривой рис. $2, b$ явственно просматривается „Плечо“ в районе длины волны $400 \mathrm{~nm}$. Близко к этим значениям длин волн находится пик плазмонного резонанса островковых пленок серебра [7]. Разумеется, атомы серебра не распределяются равномерно по поверхности подложки. Благодаря диффузии они движутся по поверхности подложки, сталкиваются, образуя кластеры, которые могут распадаться опять на отдельные атомы, а могут объединяться, образуя островки. При адсорбции количества атомов, соответствующего рис. 2, $b$, очевидно, начинается зарождение островков. Можно предположить, что для образования плазмона нужно объединение в некую структуру (кластер, островок) десятков атомов. В [12] были уверен-
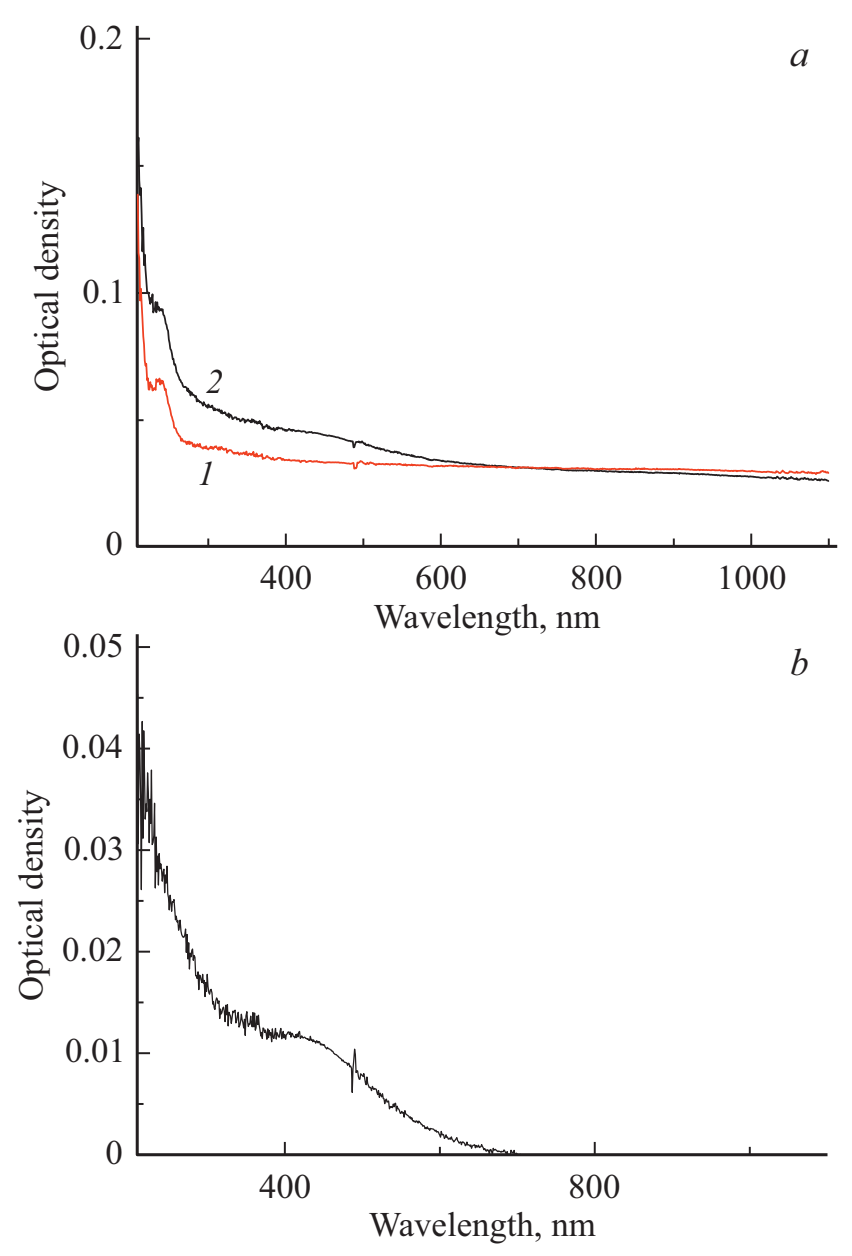

Рис. 2. (a) Спектры экстинкции подложки из плавленого кварца (1) и той же подложки с напыленной пленкой серебра (2). (b) Спектр экстинкции атомов серебра (разностный спектр). 


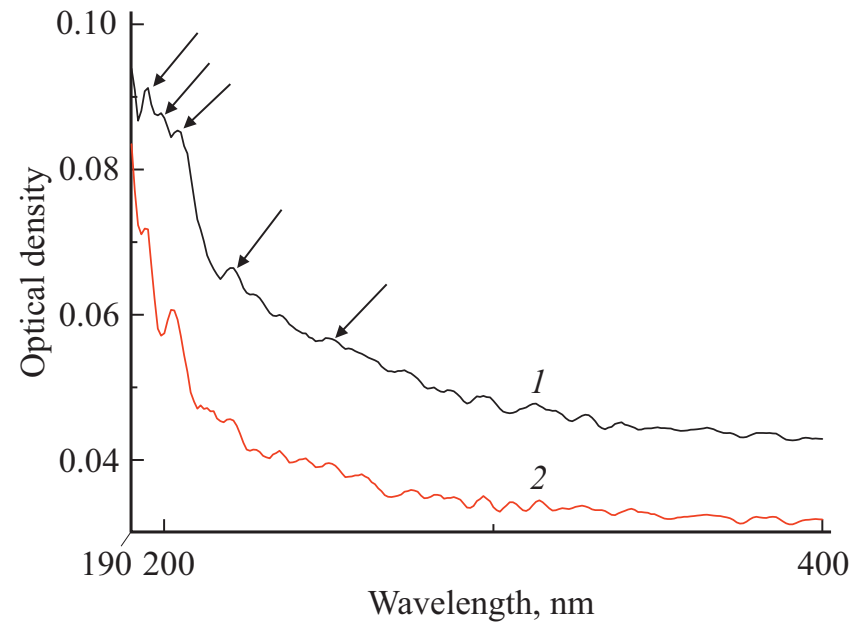

Рис. 3. Спектры поглощения кристаллического (1) и аморфного (2) кварца. Стрелками показаны особенности в спектре кристаллического кварца, соответствующие некоторым дефектам на его поверхности.

но зарегистрированы плазмоны в отдельных молекулах фуллеренов $\mathrm{C}_{60}$.

В [7] была измерена зависимость оптической плотности в полосе плазмонного резонанса серебряной островковой пленки от эффективной толщины этой пленки. Так, при толщине пленки $1 \mathrm{~nm}$ оптическая плотность составила 0.1. Сравнивая величину экстинкции в максимуме на рис. 2, $b$ с аналогичной величиной из [7], можно оценить эффективную толщину напыленной пленки. В нашем случае она оказывается около четверти монослоя.

Резкое возрастание оптической плотности плавленого кварца в районе длины волны $200 \mathrm{~nm}$, по-видимому, объясняется ростом плотности электронных состояний дефектов как в объеме подложки, так и в основном на ее поверхности.

Для исключения влияния отражения и рассеяния, которые наряду с поглощением дают вклад в измеряемую экстинкцию и могут искажать зависимость поглощения от длины волны, были получены спектры собственно поглощения для плавленого и кристаллического особо чистого кварца (примесей менее $10^{-4} \%$ для кристаллического и менее $10^{-3} \%$ для аморфного кварца) на прибоpe Shimadzu. Оказалось, что ход кривых поглощения для этих веществ очень близок к ходу кривых экстинкции на рис. 2, однако на кривых поглощения четче проявляются особенности спектра. На рис. 3 приведены зависимости оптической плотности, определяемой поглощением, от длины волны для кристаллического (грань, перпендикулярная оптической оси) и аморфного кварца.

В $[13,14]$ подробно исследовалось поглощение света дефектами в объеме плавленого кварца, а именно немостиковыми атомами кислорода. Авторы выделяют три диапазона поглощения с максимумами 2.0, 4.8 и $6.8 \mathrm{eV}$ $(622,259,183 \mathrm{~nm}$ соответственно). При этом пик с максимумом $2.0 \mathrm{eV}$ узкий (полуширина $0.17 \mathrm{eV}$ ), но интен- сивность его почти на три порядка меньше, чем пиков с максимумами 4.8 и $6.8 \mathrm{eV}$. По-видимому, эти пики соответствуют пикам на рис. 3 при 190 (виден только подъем) и $252 \mathrm{~nm}$. Небольшие различия в положении пиков можно объяснить тем, что особенности в спектрах рис. 3 в основном определяются поверхностью кварца. Пик при $622 \mathrm{~nm}$ практически не виден, что не удивительно, поскольку он существенно меньше остальных [14]. Остальные пики в спектрах рис. 3, по-видимому, можно отнести на счет других дефектов, например, $E^{\prime}$-центров (5.8 eV или $212 \mathrm{~nm}$ по данным [14]).

Ha pис. 4 показаны спектры поглощения плавленого кварца до и после напыления тонкой пленки индия, a также разностный спектр. В разностном спектре (рис. $4, b)$ просматриваются три особенности. Пик на длине волны $300 \mathrm{~nm}$ уверенно можно отнести к плазмонному резонансу индия, который четко виден в спектрах экстинкции более толстых пленок и исчезает при напылении пленок меньшей толщины. Обращает на себя внимание то обстоятельство, что в разностном спектре, т. е. на спектре, который после вычитания спектра кварца должен представлять собой спектр поглощения атомов индия, наблюдаются особенности в тех же местах,
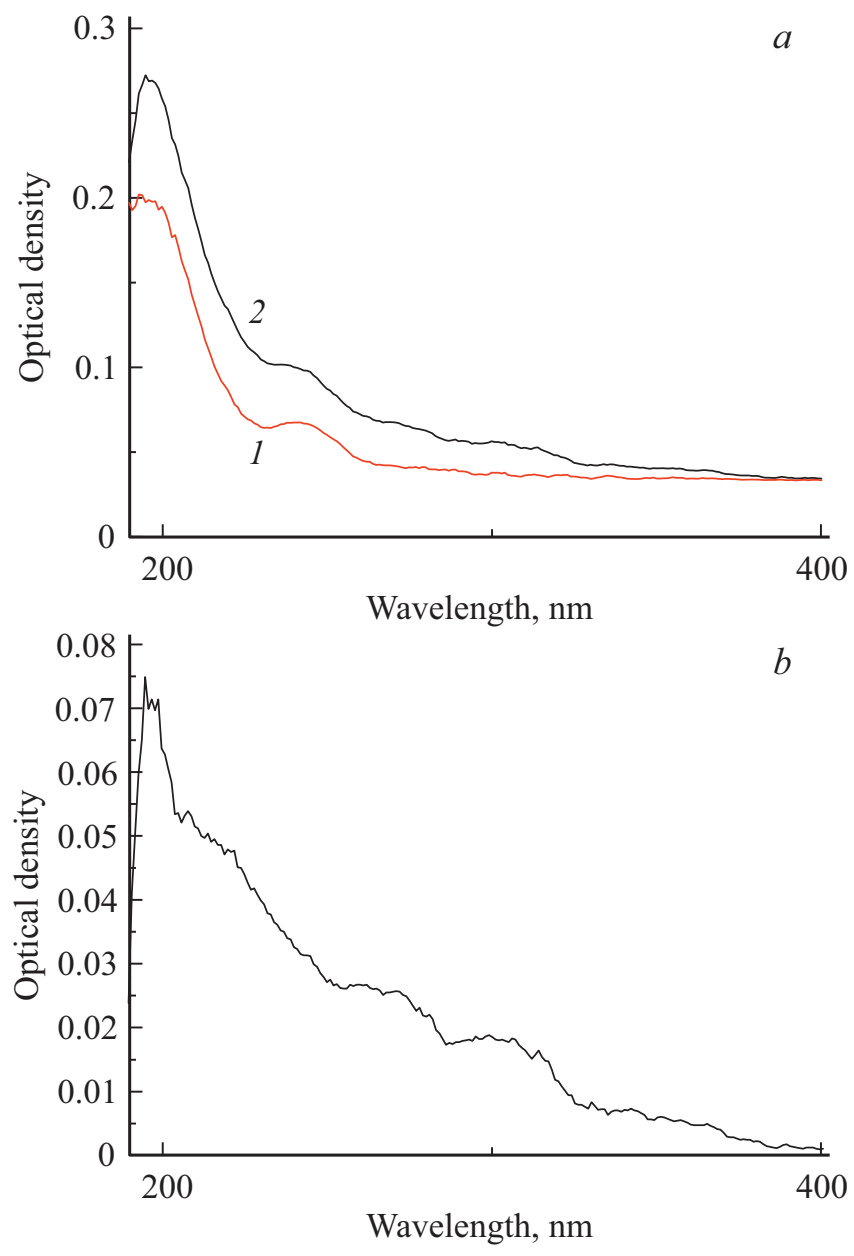

Pис. 4. (a) Спектры поглощения подложки из плавленого кварца (1) и той же подложки с напыленной пленкой индия (2). $(b)$ - разностный спектр. 
что и в спектрах кварца, как кристаллического, так и аморфного (рис. 3).

При этом после напыления пленки индия (рис. 4, $a$, кривая 2) хорошо виден рост поглощения света тем более сильный, чем больше было поглощение кварца (в диапазонах около 200 и $250 \mathrm{~nm}$ ). Подобное наблюдается и в спектрах экстинкции пленок серебра (рис. 2) и золота (рис. 1). Видно, что на длине волны около $200 \mathrm{~nm}$ наблюдается резкий рост оптической плотности.

Таким образом, приведенные выше спектры несомненно свидетельствуют о том, что напыление очень тонких пленок металла на плавленый кварц, т. е. образование комплексов „атом металла-дефект поверхности кварца“, приводит к увеличению поглощения света поверхностными состояниями кварца.

Авторы [15] с помощью теоретических моделей исследовали адсорбцию атомов меди, серебра и золота на поверхность рутила $\mathrm{TiO}_{2}(110)$ и пришли к выводу, что электрон атома металла переходит на поверхность подложки, что ведет к образованию ионов металла и, как следствие, образованию сильной связи этих ионов с мостиковыми атомами кислорода подложки. Похожий эффект описан в [16] для атомов меди, серебра и золота на поверхности кварца. По-видимому, в той или иной степени передача заряда от металла происходит и на немостиковых атомах кислорода, а также некоторых других дефектах поверхности кварца. Иначе говоря, электроны заполняют уровни Тамма на поверхности подложки, что и приводит к увеличению поглощения света.

Описанный эффект затрудняет возможность увидеть поглощение собственно атомов металла, адсорбированных на поверхности подложки в районе сильной линии поглощения этих атомов (например, для индия около $410 \mathrm{~nm}$ ), так как это было сделано в [17] для атомов натрия.

\section{Заключение}

Методом лазерной абляции получены тонкие (доли монослоя) пленки металлов на подложках из плавленого кварца. Из спектров экстинкции и спектров поглощения видно, что поглощение самого кварца резко увеличивается при длинах волн, близких к $200 \mathrm{~nm}$. Это объясняется наличием дефектов, оборванных связей - немостиковых атомов кислорода и $E^{\prime}$-центров на поверхности кварца. Показано также, что наличие атомов металла на поверхности кварца увеличивает поглощение света и это увеличение тем больше, чем больше было поглощение на поверхности чистого кварца. Это увеличение связано с передачей заряда от металла к дефектам на поверхности подложки.

Получены пленки такой толщины, при которой начинается появление островков и соответственно плазмонных резонансов.

\section{Благодарности}

Автор благодарит Т.А. Вартаняна за внимательное прочтение статьи и полезные замечания.

\section{Финансирование работы}

Работа выполнена при государственной финансовой поддержке ведущих университетов Российской Федерации (субсидия 08-08).

\section{Конфликт интересов}

Авторы заявляют, что у них нет конфликта интересов.

\section{Список литературы}

[1] Lopez N., Illas F., Pacchioni G. // J. Am. Chem. Soc. 1999. V. 121. N 4. P. 813.

[2] Xueping Xu, Jian-Wei He, Goodman D.W. // Surface Sci. 1993. V. 284. N 1-2. P. 103.

[3] Brause M., Ochs D., Gtinster J., Mayer Th., Braun B., Puchin V., Maus-Friedrichs W., Kempter V. // Surface Science. 1997. V. 383. P. 216-225.

[4] Flank A.M., Delaunay R., Lagarde P., Pompa M. // Phys. Rev. B. 1996. V. 53. N 4. P. R1737-R1739.

[5] Kumagai R., Hatakeyama A. // Appl. Phys. B. 2016. V. 122. P. 186. doi 10.1007/s00340-016-6457-1

[6] Richey N.E., de Paulala C., Bent S.F. // Chem. Phys. 2020. V. 152. 040902.

[7] Леонов Н.Б., Гладских И.А., Полищук В.А., Вартанян T.A. // Опт. и спектр. 2015. Т. 119. № 3. C. 116; Leonov N.B., Gladskikh I.A., Polishchuk V.A., Vartanyan T.A. // Opt. Spectrosc. 2015. V. 119. N 3. P. 450.

[8] Griscom D.L. // J. Non-Cryst. Solids. 1977. V. 24. N 2. P. 155.

[9] Некрашевич С.С., Гриценко В.А. // ФТТ. 2014. Т. 56. В. 2. C. 209.

[10] Baonan Jia, Zixuan Guan, Ruge Quhe, Zhixing Peng, Jie Zhang, Xiaoning Guan, Jun Chen, You Wang, Pengfei Lu // J. Non-Cryst. Solids. 2018. V. 497. P. 7. doi 10.1016/j.jnoncrysol.2018.05.030

[11] Леонов Н.Б. // Опт. и спектр. 2019. Т. 127. № 10. С. 696; Leonov N.B. // Opt. Spectrosc. 2019. V. 127. N 4. P. 750.

[12] Keller J.W., Coplan M.A. // Chem. Phys. Lett. 1992. V. 193. P. 89.

[13] Hosono H., Kajihara K., Suzuki T., Ikuta Y., Skuja L., Hirano M. // Sol. State Commun. 2002. V. 122. N 3-4. P. 117.

[14] Suzuki T., Skuja L., Kojihara K., Hirano M., Kamiya N., Hosono H. // Phys. Rev. Lett. 2003. V. 90. N 8. 186404-1186404-4.

[15] Giordano I., Pacchioni G., Bredow T., Fernandez Sanz J. // Surface Sci. 2001. V. 471. P. 21.

[16] Ferullo R.M., Garda G.R., Belelli P.G., Branda M.M., Castellani N.J. // TEOCHEM. 2006. V. 769. P. 217.

[17] Бонч-Бруевич А.М., Вартанян Т.А., Максимов Ю.Н., Пржибельский С.Г, Хромов В.В. // Изв. АН, сер. физ. 1997. T. 61. № 7. C. 1315. 